\title{
Has the Implementation of MLE Improved the Achievements in Thailand's Deep South?
}

\author{
Yapar Cheni ${ }^{1}$, Suppaluk Sintana ${ }^{2}$, Supa Watcharasukum ${ }^{1}$, Pimonpun Leelapatarapun ${ }^{3}$, Pranee Lumbensa ${ }^{2}$, \\ Phimpawee Suwanno ${ }^{2}$, Anas Rungwittayapun ${ }^{3}$, Niharong Tohsu ${ }^{2}$, Armeenoh Deemae ${ }^{2} \&$ Niyamal Ayae $^{2}$ \\ ${ }^{1}$ Faculty of Humanities and Social Sciences, Yala Rajabhat University, Yala, Thailand \\ ${ }^{2}$ Faculty of Education, Yala Rajabhat University, Yala, Thailand \\ ${ }^{3}$ Faculty of Science, Technology and Agriculture, Yala Rajabhat University, Yala, Thailand \\ Correspondence: Yapar Cheni, Faculty of Humanities and Social Sciences, Yala Rajabhat University, Yala, \\ Thailand. Tel: 66-86-293-8957. E-mail: yapar_cheni@yahoo.co.in
}

Received: April 17, $2017 \quad$ Accepted: June 2, $2017 \quad$ Online Published: July 26, 2017
doi:10.5539/ijel.v7n5p54
URL: http://doi.org/10.5539/ijel.v7n5p54

\begin{abstract}
Long-term evaluations of student performance are important to show whether Multilingual Education (MLE) students are making real progress, as well as to show what changes are needed to make MLE programs more successful. The purpose of this paper is to describe a six-year study of MLE students in Southern Thailand. .In 2007, the Research Institute for Languages and Cultures of Asia, Mahidol University (RILCA-MU) initiated the Patani Malay-Thai Bi/multilingual Research Project in four schools in Southern Thailand. In 2011, the Yala Rajabhat University (YRU) staff began biannual student evaluations of both the experimental (MLE) schools and the "normal" Thai-only comparison schools, when the first cohort of students began primary grade 1. YRU followed these students' performances until 2016 when they completed primary grade 6 . The learning achievement for students in the experimental (MLE) schools was found to be significantly higher than that of students in the comparison schools at the level of 0.01, except in grade 6 . The number of students who met the basic educational criteria was greater for the MLE schools than the comparison schools. MLE was found to be very helpful for low and mid-level performing student. Finally, scores on the critical thinking skills assessment of the MLE students were greater than the comparison school students. Thus, this six-year research project has clearly shown that MLE can help to solve the problems of teaching and learning in Thailand's three southern border provinces. This approach to long-term evaluations can be helpful to projects in other countries also.
\end{abstract}

Keywords: bilingual education, multilingual education, student achievement, southern Thailand, Patani Malay

\section{Introduction}

\subsection{Introduction of the Study}

In the compulsory education system of Thailand, the Thai language is the only medium of instruction used. As a result, numerous content of learning areas in the curriculum lacks the support of communication and critical thinking and is not consistent with local society learning conditions (Fahrungsang et al., 2011). Moreover, the political and economic crisis in the three southern border provinces (the Deep South) that are Pattani, Yala, and Narathiwat has acted as an obstacle to the development of the education system in Thailand. It has been recognized that these crises have affected the learning achievement of young children in the southern provinces that fell below the benchmark level (National Institute of Educational Testing Service, 2009). Some young children are unable to pursue their education at a higher level and thus lack in using their knowledge and skills at a professional level in order to live harmoniously in a diverse society and to improve the quality of life for sustainable happiness (Chailangka, 2006)

\subsection{Importance of the Problem}

The Center for Documentation and Revitalization of Endangered Language, the Research Institute for Languages and Cultures of Asia, Mahidol University (RILCA-MU), 2010, highlighted the six methods used by Thomas and Collier to investigate traditional instructions and bilingual education. Compiling data from 42,000 learners and $7,000,000$ records on student achievements over a period of 14 years he came to a conclusion that only bilingual education, one out of five methods, can provide the growth and development opportunity of a low academic 
proficiency. The bilingual education has the advantage of providing learning achievement in both mother tongue and second languages for the ethnic students. The research suggested that education should serve the whole community in sociocultural aspects as well. It was in line with Chaipong et al. (2007) who suggested that the development of the brain and the thinking process is linked with receiving and learning educations in the Thai language subject.

\subsection{Significance of the Study}

A long-term research on bi/multilingual education has been conducted by RILCA-MU on using Patani Malay (PM) and Thai as a medium of instruction in the Deep South of Thailand. Classes started in each of experimental schools from kindergarten to the sixth grade. The teaching was based on a systematic connection between the language and culture in children and schools. It also focused on the use of dialects as a key to learning. The most important tool in the connection between PM and Thai was firstly the knowledge of the students and culture at home. Secondly, Thai as their new knowledge and culture at schools by using a system of writing as the medium of instruction. It was the evolution of writing Malay dialects with Thai alphabets. Content and teaching materials had been designed in relation to the culture and lifestyle of students. On the other hand, teaching strategies were designed to focus on improving the language skills of children with brain development in parallel with the development of society and culture. It aimed at strengthening the children to succeed in education by using the knowledge in order to improve the quality of life. Further, the goals are to encourage the appreciation of local culture by enabling them to perform their proper cultural identity at the local level as well as being Thainess at the national level.

YRU has collaborated with Mahidol University (MU) to evaluate the student achievement of MLE program implemented in three schools in the Deep South. This article is a part of the project that aimed to evaluate the effectiveness of the PM-Thai Bilingual Education. However, the finding would be an important indicator of the success of the bilingual education as well as information on how to improve its implementation and to develop suitable forms of education in schools. It would also contribute to solving the education problems of young Thai Muslims and henceforth may act as a tool in imposing education policy in the Deep South.

\subsection{Research Objectives}

The objective of the study is to evaluate the achievement of the MLE program using PM and Thai. These languages are intended to be used as a medium of instruction for the first cohort of students who had studied from grades 1 to 6 in the Deep South. The objectives are specific as follows: (1) To compare the learning achievement between students in the experimental schools (providing PM-Thai Bilingual Education) and those in the comparison schools (providing normal "only Thai" education), (2) To compare the percentage of students who met the criteria (50 percent of cutoff score) between those in the experimental and comparison schools, (3) To compare the critical thinking skills in science of the sixth graders in the experimental schools and comparison schools, and (4) To compare the percentage of the sixth graders who met the criteria in critical thinking skills in science between that of the experimental and comparison schools.

\section{Methodology}

\subsection{Method}

In this study, the researchers evaluate the first cohort of the students who had studied from grades 1 to 6 during the academic year 2010 to 2015 in six schools (three for the experimental schools and the rest for the comparison schools) in the Deep South of Thailand.

\subsection{Materials}

The instruments were the achievement tests of three learning areas including mathematics, science, Thai language, and reading skills developed through a construction process of a standard test. 3 out of 9 experts teaching at the elementary level were recruited to analyze curriculum, to write behavioral objectives, and to construct the tests in each subject. The 3 to 5 experts examined the tests to determine the Index of Item Objective Congruence (IOC) at each level. They are from universities and Primary Educational Service Area Offices (PESAO). Being the only items with IOC $>0.5$ value was selected for a tryout with approximately 100 students in similar types of the research sample to determine instrument quality, i.e. the difficulty index, discrimination index, and the reliability. Then only items that met the validation criteria were chosen for inclusion in a real test of elementary student samples to attempt in late February to early March for six years. In each year, the researchers would carry out the tests in different ways to suit the development of student language. The followings were the procedure of the tests in each year. 


\subsection{Participants and Procedures}

In 2010, the first graders both in the experimental and the comparison schools attempted the tests with multiple-choice questions about the same content. In the comparison schools, they were provided with the "Thai-only" tests, whereas those in the experimental schools with the tests were translated into PM. The instructions and items in the paper had been read to the examinees two times per item by the trained YRU students as local research assistants. After reading, the examinees were required to choose the correct answer out of possible answers in the exam paper. They would be read and done in all five learning areas. In addition to Thai language and reading skills, the examinees had attempted a practical part of the test in order to assess in reading aloud as well.

In 2011, the second graders tried the tests similar to the previous year in 2010, whereas the instructions and items in the paper had been read to the examinees only one time per item by the research assistants.

In 2012, the third graders attempted the tests similar to the previous years in 2010 and 2011, whereas the assistants would not read instructions and items in the paper anymore. Ensuring the examinees read and attempted the exam papers by themselves.

In 2013, the fourth graders attempted the same "Thai-only" tests in all three learning areas. While in reading skills, emphasized was made on reading comprehension. The tests comprised of two sets, namely, the comparison students were provided with the "Thai-only" tests, whereas those in the experimental schools with the tests translated into PM.

In 2014, the fifth graders attempted the same "Thai-only" tests in all three learning areas, and in reading skills, the tests emphasized on reading comprehension and critical thinking. The "Thai-only" tests were provided in both the experimental schools as well as in the comparison schools.

In 2015, the sixth graders, the first cohort of the bilingual students attempted the tests similar to the previous year in 2014. The tests included two more instruments in order to collect additional data, i.e., a behavioral questionnaire and a critical thinking questionnaire. The data were subjected to statistical analysis by using t-test and effect size (d) using a software package.

\section{Results}

In the evaluation of learning achievement of the PM-Thai Bilingual Education, the data were as follows:

\subsection{Overall Achievement}

Firstly, in comparing results, the average score of the overall achievement of the experimental students in three learning areas and reading skills was significantly higher than that of the comparison school students during the year 2010 to 2015. The results were extremely significant almost in all grades at the .01 level, except only in grade 6 . In grade 6 it was differentiated with a large effect size $(\mathrm{d}>1.00)$ between the experimental schools and the comparison schools when they were in grade 1.

The score was reduced to a medium effect size $(\mathrm{d}=0.5)$ in grade 3 and 5 . The overall learning achievement of the students showed no statistically significant difference. In other words, it can be stated that there was no difference between the experimental and the comparison schools when they were in grade 6 as detailed in Table 1.

Table 1. The comparison of learning achievement of the students between the experimental and the comparison schools

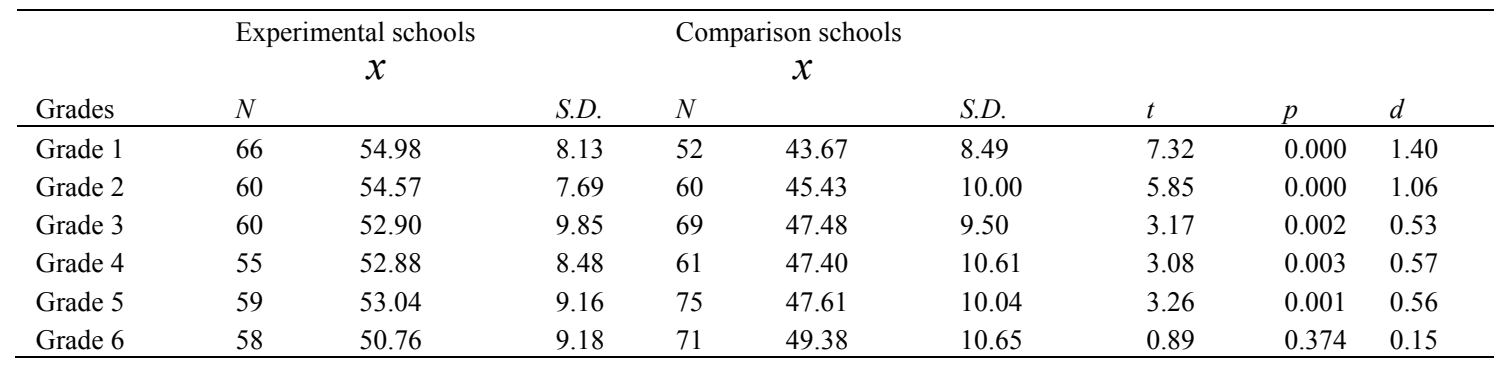




\subsection{Achievement by Subjects and Grade Levels}

The learning achievements in each subject were then compared as detailed in Table 2.

Table 2. The comparison of learning achievement in each subject of the students between the experimental and the comparison schools during the academic years 2010 to 2015

\begin{tabular}{|c|c|c|c|c|c|c|c|c|c|}
\hline \multirow[b]{3}{*}{ Subjects } & \multicolumn{3}{|c|}{ Experimental schools } & \multicolumn{6}{|c|}{ Comparison schools } \\
\hline & \multicolumn{3}{|c|}{$x$} & \multicolumn{3}{|c|}{$x$} & \multirow[b]{2}{*}{$t$} & \multirow[b]{2}{*}{$p$} & \multirow[b]{2}{*}{$d$} \\
\hline & $N$ & & S.D. & $n$ & & S.D. & & & \\
\hline \multicolumn{10}{|l|}{ Grade 1 in the academic year 2010} \\
\hline Science & 66 & 53.96 & 7.03 & 52 & 44.97 & 10.97 & 5.14 & 0.000 & 0.95 \\
\hline Mathematics & 66 & 54.27 & 8.91 & 52 & 44.58 & 8.64 & 5.97 & 0.000 & 1.10 \\
\hline Thai language & 66 & 53.86 & 9.43 & 52 & 45.07 & 7.47 & 5.34 & 0.000 & 0.99 \\
\hline Reading skills & 66 & 54.86 & 8.35 & 52 & 43.84 & 8.45 & 7.07 & 0.000 & 1.31 \\
\hline Total 3 subjects and reading skills & 66 & 54.98 & 8.13 & 52 & 43.67 & 8.49 & 7.32 & 0.000 & 1.40 \\
\hline \multicolumn{10}{|l|}{ Grade 2 in the academic year 2011} \\
\hline Science & 60 & 53.00 & 8.39 & 60 & 47.00 & 10.63 & 3.43 & 0.001 & 0.62 \\
\hline Mathematics & 60 & 50.81 & 9.89 & 60 & 49.19 & 10.13 & 0.89 & 0.377 & 0.16 \\
\hline Thai language & 60 & 53.00 & 9.83 & 60 & 47.00 & 9.32 & 3.43 & 0.001 & 0.62 \\
\hline Reading skills & 60 & 56.22 & 5.23 & 60 & 43.78 & 9.77 & 8.69 & 0.000 & 1.58 \\
\hline Total 3 subjects and reading skills & 60 & 54.57 & 7.69 & 60 & 45.43 & 10.00 & 5.85 & 0.000 & 1.06 \\
\hline \multicolumn{10}{|l|}{ Grade 3 in the academic year 2012} \\
\hline Science & 60 & 52.37 & 10.17 & 69 & 47.94 & 9.45 & 2.56 & 0.012 & 0.45 \\
\hline Mathematics & 60 & 51.39 & 10.42 & 69 & 48.79 & 9.53 & 1.47 & 0.143 & 0.26 \\
\hline Thai language & 60 & 53.06 & 10.59 & 69 & 47.34 & 8.68 & 3.37 & 0.001 & 0.59 \\
\hline Reading skills & 60 & 52.86 & 8.31 & 69 & 47.51 & 10.71 & 3.19 & 0.002 & 0.55 \\
\hline Total 3 subjects and reading skills & 60 & 52.90 & 9.85 & 69 & 47.48 & 9.50 & 3.17 & 0.002 & 0.53 \\
\hline \multicolumn{10}{|l|}{ Grade 4 in the academic year 2013} \\
\hline Science & 55 & 53.74 & 9.24 & 61 & 46.63 & 9.51 & 4.08 & 0.000 & 0.75 \\
\hline Mathematics & 55 & 51.73 & 8.89 & 61 & 48.44 & 10.74 & 1.80 & 0.075 & 0.33 \\
\hline Thai language & 55 & 51.31 & 8.48 & 61 & 48.82 & 11.14 & 1.36 & 0.176 & 0.25 \\
\hline Reading skills & 55 & 52.69 & 8.98 & 61 & 47.57 & 10.32 & 2.85 & 0.005 & 0.53 \\
\hline Total 3 subjects and reading skills & 55 & 52.88 & 8.48 & 61 & 47.40 & 10.61 & 3.08 & 0.003 & 0.57 \\
\hline \multicolumn{10}{|l|}{ Grade 5 in the academic year 2014} \\
\hline Science & 59 & 54.34 & 10.14 & 75 & 46.58 & 8.50 & 4.71 & 0.000 & 0.82 \\
\hline Mathematics & 59 & 51.26 & 9.03 & 75 & 49.01 & 10.65 & 1.32 & 0.188 & 0.23 \\
\hline Thai language & 59 & 52.54 & 9.23 & 75 & 48.00 & 10.18 & 2.70 & 0.008 & 0.47 \\
\hline Reading skills & 59 & 52.24 & 8.85 & 75 & 48.24 & 10.18 & 2.38 & 0.019 & 0.41 \\
\hline Total 3 subjects and reading skills & 59 & 53.04 & 9.16 & 75 & 47.61 & 10.04 & 3.26 & 0.001 & 0.56 \\
\hline \multicolumn{10}{|l|}{ Grade 6 in the academic year 2015} \\
\hline Science & 58 & 52.01 & 9.47 & 71 & 48.36 & 10.19 & 2.10 & 0.037 & 0.37 \\
\hline Mathematics & 58 & 49.38 & 9.58 & 71 & 50.51 & 10.37 & -0.64 & 0.521 & -0.11 \\
\hline Thai language & 58 & 50.78 & 9.77 & 71 & 49.36 & 10.21 & 0.91 & 0.421 & 0.16 \\
\hline Reading skills & 58 & 51.14 & 9.56 & 71 & 49.07 & 10.32 & 1.18 & 0.239 & 0.20 \\
\hline Total 3 subjects and reading skills & 58 & 50.76 & 9.18 & 71 & 49.38 & 10.65 & 0.89 & 0.374 & 0.15 \\
\hline
\end{tabular}

The table showed that the learning achievement of the students in the experimental schools was higher than that of the students in the comparison schools. The scores were statistically significant in grades 1 to 5 in almost every subject and in grade 4 in the Thai language, except in grades 2 to 5 in mathematics.

Further, the table indicates that the learning achievement of the students in the experimental schools was higher than that of the students in the comparison schools statistically significant at the .05 level only in science by grade 6.

The bar graphs below analysis the comparisons of the differences between the learning achievements of the first cohort of the students in the experimental schools and the students in the comparison schools in each grade as in Figure 1. 

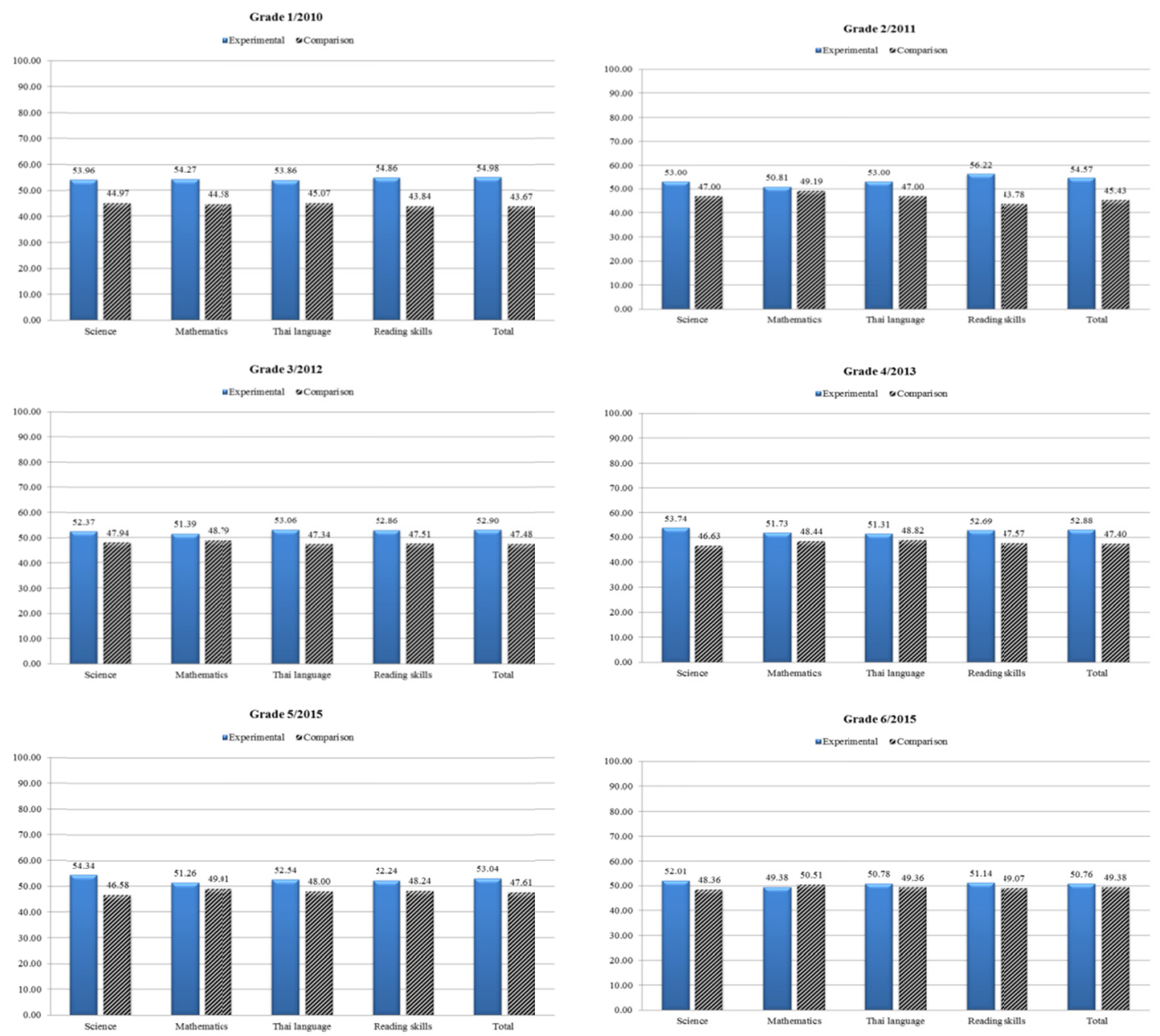

Figure 1. The bar graphs analysis the comparisons of the differences in each grade between the learning achievement of the first cohort of students in the experimental schools and that of the students in the comparison schools

\subsection{Numbers and Percentages of the Students Meeting the Criteria}

Secondly, in comparing the results between the two schools, a criterion of 50 percent of the cutoff score was set on the basis of percentage. It was evaluated by the score that the percentage of the students in the experimental schools meeting the criteria, was higher in all grades and subjects, except in mathematics, grade 6 (shown in Table 3) than that of the students in the comparison schools.

Similarly, in terms of subject, it can be analyzed that the numbers of students in the experimental schools outnumbered those of students in the comparison schools almost in every subject with regards to the criteria except in mathematics for grade 6 that the number was less than the comparison schools. 
Table 3. The comparison of numbers and percentages of the students who met the criteria by grades between the experimental and comparison schools

\begin{tabular}{|c|c|c|c|c|c|c|c|}
\hline \multirow[b]{2}{*}{ Subjects \& Schools } & \multicolumn{7}{|c|}{ (Numbers) Percentages } \\
\hline & $\begin{array}{l}\text { Grade } 1 \text { in } \\
2011\end{array}$ & $\begin{array}{ll}\text { Grade } & 2 \\
2012 & \\
\end{array}$ & in & $\begin{array}{l}\text { Grade } 3 \text { in } \\
2013\end{array}$ & $\begin{array}{l}\text { Grade } 4 \text { in } \\
2014\end{array}$ & $\begin{array}{l}\text { Grade } 5 \text { in } \\
2015\end{array}$ & $\begin{array}{l}\text { Grade } 6 \text { in } \\
2016\end{array}$ \\
\hline \multicolumn{8}{|l|}{ Science } \\
\hline Experimental schools & (53) 80.30 & (41) 68.33 & & (39) 65.00 & (36) 65.45 & (40) 67.80 & (36) 62.07 \\
\hline $\begin{array}{l}\text { Comparison Schools } \\
\text { Mathematics }\end{array}$ & (18) 34.61 & (23) 38.33 & & (29) 42.02 & (24) 39.34 & (25) 33.33 & (32) 45.07 \\
\hline Experimental schools & (41) 62.12 & (27) 45.00 & & (39) 65.00 & (33) 60.00 & (36) 61.01 & (25) 43.10 \\
\hline Comparison Schools & (9) 17.30 & (29) 48.33 & & (37) 53.62 & (26) 42.62 & (41) 54.67 & (37) 52.11 \\
\hline \multicolumn{8}{|l|}{ Thai language } \\
\hline Experimental schools & (45) 68.18 & (40) 66.67 & & (41) 68.33 & (36) 65.45 & (36) 61.01 & (34) 58.62 \\
\hline Comparison Schools & (14) 26.92 & (16) 26.67 & & (25) 36.23 & (34) 55.74 & (30) 40.00 & (37) 52.11 \\
\hline \multicolumn{8}{|l|}{ Reading skills } \\
\hline Experimental schools & (52) 78.79 & (57) 95.00 & & (41) 68.33 & (38) 69.09 & (41) 69.50 & (30) 51.72 \\
\hline Comparison Schools & (15) 28.84 & (21) 35.00 & & (28) 40.59 & (24) 39.34 & (35) 46.67 & (28) 39.44 \\
\hline \multicolumn{8}{|c|}{ Total in 3 subjects and Reading skills } \\
\hline Experimental schools & (49) 74.24 & (46) 76.67 & & (45) 75.00 & (39) 70.90 & (38) 64.40 & (30) 51.72 \\
\hline Comparison Schools & (12) 23.08) & (21) 35.00 & & (27) 39.13 & (25) 40.98 & (33) 44.00 & (37) 52.11 \\
\hline
\end{tabular}

The bar graphs below (Figure 2.) demonstrate the comparisons of differences between the percentages of student who met the criteria in each grade within the two schools. Considering the total scores, it can be evaluated that the numbers of the students in the experimental schools who met the criteria were higher in number than those of the students in the comparison schools in grades 1 to 5 , except in grade 6 .

\subsection{Differences in Critical Thinking in Science}

Third, it was found that a statistical difference existed at the .01 level of significance with a medium effect size $(d=0.65)$, shown in table 4 for comparative results in terms of differences in critical thinking in science between the cohort students by grade 6 in the experimental schools and those in the comparison schools

Table 4. The comparison of the learning achievement of critical thinking skills in science between the sixth graders in the experimental schools and those in the comparison schools

\begin{tabular}{lllllll}
\hline Types of School & $N$ & $x$ & $S . D$. & $t$ & $p$ & $d$ \\
\hline Experimental schools & 58 & 53.41 & 9.53 & & & \\
Comparison schools & 71 & 47.21 & 9.56 & 3.67 & 0.00 & 0.65 \\
Total & 129 & 50.00 & 10.00 & & & \\
\hline
\end{tabular}

\subsection{The Cohort Students Met the Criteria in Critical Thinking in Science}

Finally, in comparison of numbers and percentages between the first cohort of students by grade 6 who met the criteria in critical thinking of science in the experimental schools and those in the comparison schools, it was found that the number and the percentage of the students in the experimental schools outnumbered those in the comparison schools, as shown in Table 5.

Table 5. The comparison of the numbers and percentages between the first cohort of students at grade 6 who met the criteria in critical thinking of science in the experimental schools and those of the students in the comparison schools

\begin{tabular}{|c|c|c|c|c|c|}
\hline \multirow[b]{2}{*}{ Types of School } & \multirow[b]{2}{*}{$n$} & \multicolumn{2}{|c|}{ Criteria Met } & \multicolumn{2}{|c|}{ Criteria Not Met } \\
\hline & & Numbers & Percentages & Numbers & Percentages \\
\hline Experimental schools & 58 & 36 & 62.07 & 22 & 37.93 \\
\hline Comparison schools & 71 & 32 & 45.07 & 39 & 54.93 \\
\hline Total & 129 & 68 & 52.71 & 61 & 47.29 \\
\hline
\end{tabular}



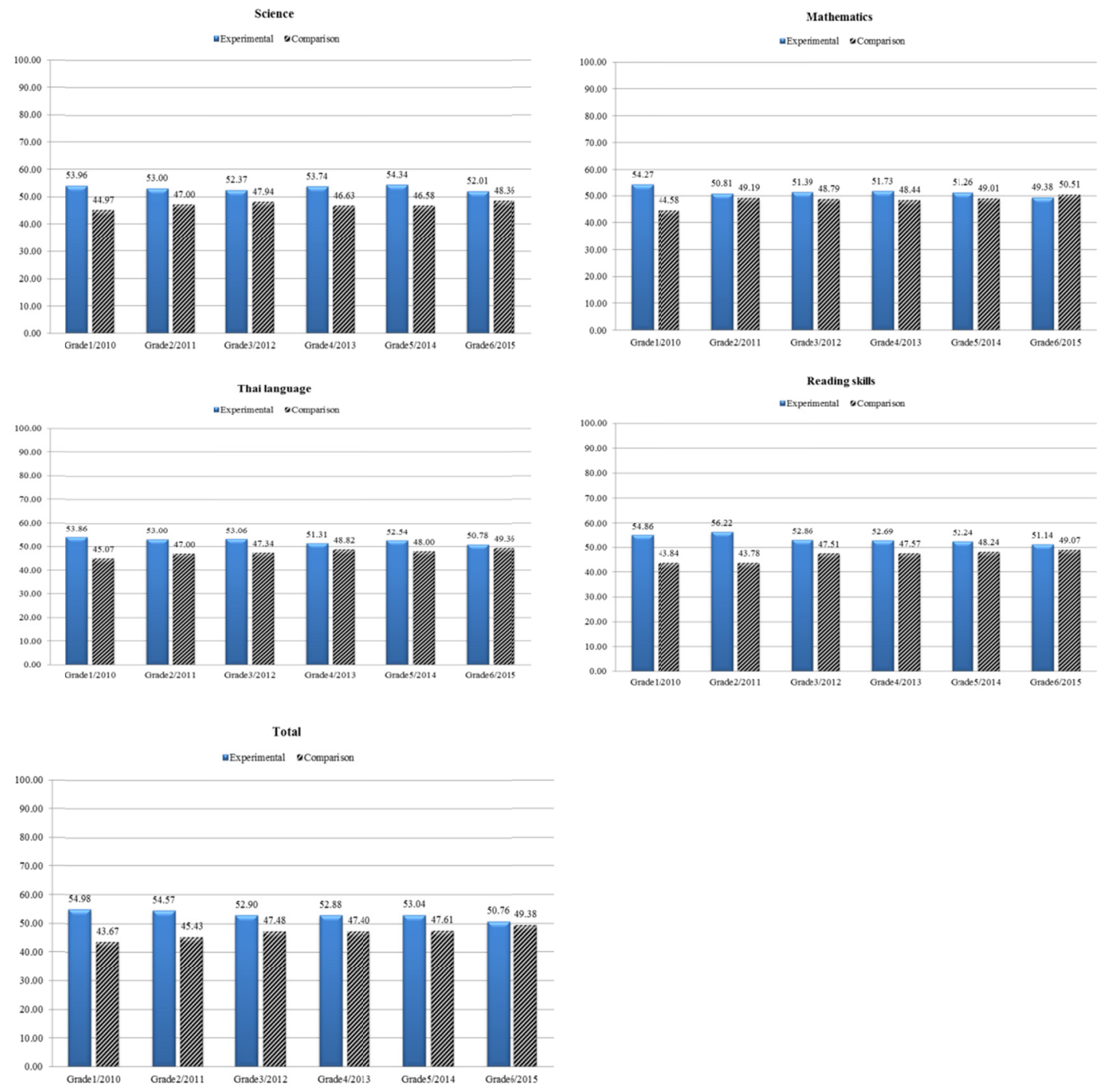

Figure 2. The bar graphs showed the comparison of differences by learning areas between the percentages of student who met the criteria in each grade within the experimental and comparison schools during the academic years of 2010 and 2015

\section{Discussion}

Based on the findings of this study, the learning achievement of the students in the experimental schools studied over 5 years from grades 1 to 5 that was higher than that of the students in the comparison schools. The numbers and percentages of the students who met the criteria in the experimental schools had outnumbered those in the comparison schools. According to the results, the data seem to be a supportive data for PM-Thai Bilingual Education. This is consistent with the findings of Thomas and Collier (as cited in the Resource Center for Revitalization and Maintenance of Endangered Languages and Cultures, RILCA-MU, 2010). Thomas and collier research stated that the ethnic students using mother tongue [L1] together with the second language [L2] in the development of their learning and academic performance reached significantly higher levels of achievement than other learning approaches. Adding more, the data was consistent with the findings of Chaipong et al. (2007). He highlighted the importance of using dialects in schools to link into an official language in a teaching process. As the author recognized that the development of young's brain and thinking system benefited children's learning in the Thai language subject.

However, based on the findings of this study, unlike the assessment results in the past five years, there was no significant difference in the overall learning achievement of the sixth graders within the two schools. This was probably due to the following reasons. 
First, school administrators considerably focused on Ordinary National Educational Test (O-NET) while the teachers used the same learning methods. Nearly all schools provided tutoring to students, on the school level, the teachers supplied exam papers for tutoring the students in preparation for the O-NET test, individually and in school-group level. Further, the teachers provided tutoring at a time close to the examination date. The school network operated programs in upgrading learning achievement for the students. The network demonstrated a plan for assigning a task to the qualified, experienced teachers on the basis of their expertise. As a result, the students in both the experimental and comparison schools got the tuition from the same teachers, except the schools No. 3. All schools, intended to provide tutoring to their students earnestly, and they would like to score higher in O-NET test not less than 5 percent than the past academic years.

Also, the experimental school teachers did not use a bilingual teaching plan according to the form of training and did neither follow bilingual teaching steps. Therefore, the students' potentiality had not been developed in accordance with the target set by the MLE program. Moreover, it was explored that the students were never trained up to raise a question, to connect from known to unknown knowledge to developing a thinking process. The lack of developing the thinking process was seen from the teacher as the teaching strategy that was followed the required students to memorize the knowledge as a teacher-centered approach. This phenomenon had happened continuously since the students took National Test (NT) by grade 3 in the academic year 2012, and even more intensive when they had to take O-NET examination by grade 6 in the academic year 2015 (Sintana et al, 2013).

Secondly, students failed to realize an importance of the exam. Evidence can be taken from Reading skills, where the students were assigned to read a story for comprehension and think critically to answer the questions. The comprehension was mostly based on culture, history and background of landmarks in a community, and major tourist attractions in the Deep South. It was noted that during conducting and supervising the exam, the students were not willing to read the questions as the exam was conducted in the afternoon thus leading them to attain lower marks. As shown in the research paper, the students of the experimental and the comparison schools scored below than 50 percent in Reading skills which was lower than other subjects. Consistent with the findings of Dumpheng (2013) and Linchareon et al. (as cited in Chaiwong, 2012), the factor that caused the sixth graders to score a lower mark in O-NET was the failure of the students in realizing the importance of exams or giving a less priority to the exam. This was due to the lack of awareness of when and what the test results are to be used. O-NET and YRU evaluation tests had not affected their passing or failing of class. As a result, the students in both the experimental and the comparison schools did not realize the importance of exams and lacked the willingness to take the exam as well. An interesting issue was that the experimental school students had always outscored higher in reading skills than those in the comparison schools during the academic years 2010 to 2014, but in this exam, it was found that there was no difference between them. By grade 6, the students in the experimental schools tended to score lower in Reading skills achievement compared with their previous year. The major cause was by not giving priority to the examinations of the students as mentioned above and due to the frequent exams of the sixth graders, students were reluctant to attempt any more test. As noted, "The students do not read the test papers at all and they tick and check answers of each item. When we get closer to them, they act as if to pick up the paper to read" (Sintana et al., observation on March 9, 2014). Furthermore, the team of MU observing students of the experimental school No. 7 took another test of Islamic National Test (I-NET) in addition to O-NET and YRU tests.

Third, another finding was the teachers could not complete the course. Based on the interviews and focus group discussions, it is indicated that almost all or most of the teachers had not completed the course resulting in an incomplete teaching course. As a result, the students in the experimental and the comparison schools scored fewer marks in various subjects with the same learning behavior. The highlighted reason was selecting the answers of multiple choice questions on blind guess due to incomplete teaching course and because of merely memorizing the content. Thus, no difference was seen in academic achievement between the students in the experimental and the comparison schools. The reason behind the incomplete teaching course was due to a heavy workload on teachers. In addition to teaching, almost all teachers were responsible for other tasks as decentralization in schools increased the workload of teachers. According to the administrative structure the teachers are assigned with four different tasks that are academic administration, personnel management, budget management, and the duties in accordance with the policy of original affiliation. There were also other projects that required collaboration with outside agencies as well. As a result, the teachers were unable to teach properly (Dumpheng, 2013).

Fourth, it is noted that by grade 1 the starting point of evaluation of the project, learning and teaching and cooperation strategies were undertaken seriously by all parties including the teachers and the school 
administrators. The research team of the MLE project from MU served to develop bilingual lesson plans by providing training for implementation of instructional strategies in accordance to MLE lesson plans and adequate supports of teaching materials.

By grade 1, well trained permanent teachers and teacher assistants (TA) were intensely operating together by using MLE approach. Through the MLE program, the teachers understood the exact purpose of their teaching tasks and their roles in the same direction. While the difference in the learning achievement of the students between the experimental and the comparison schools was statistically significant at the .01 level. Moreover, during four years of monitoring and evaluation of the program, three administrators had been replaced in a school. As a result, there was a change of the administrators in the MLE schools. This act was regarded as an important factor affecting teacher's performance in the MLE schools. Hence it was realized that an administrator and the administration department are important mechanisms in motivating a teacher to undertake a training program. Further, it is an important factor in ensuring that the bilingual education system is used seriously and continuously.

Finally, a change was witnessed in class-level for the 6 years long term evaluation. The change reflected the implementation of the MLE system in the experimental schools. During the evaluation and monitoring period, it was analyzed that some of the teachers did not seriously and continuously act on MLE instructional strategies and lesson plans. As a result, there was no significant difference in some subjects among the students in the experimental schools and the comparison schools.

Consequently, the finding of this assessment was seen as a challenge for the future learning achievement or learning outcome in terms of implementing MLE instructional strategies. The question was raised whether the MLE approach would seriously be followed or not for the students in the experimental schools and whether the score would be higher than those in the comparison schools with regular education or not. However, the MLE in neighboring countries like the Philippines and Vietnam was consistent with Sintana et al. (2014). MLE in the experimental schools focused on the development of thinking and speaking skills of the students. As a result, the strategy has made the learning achievement of the students in the experimental schools higher than that of the students in the comparison schools. Similarly, the findings of Laemtrakul et al. (2013) on the assessment of the learning achievement of multilingual education of ethnic students in the northern part of Thailand during the academic year of 2011-2012, suggested that the students of the MLE program had improved their learning achievement respectively.

The results are shown in Table 4 and 5, indicates the critical thinking skills of the students in the experimental schools in science are higher than those of the students in the comparison schools $\left(\overline{\mathrm{X}}_{\text {experimental }}=53.41\right.$ and $\overline{\mathrm{X}}$ comparison $=47.21$ ). Moreover, the numbers and percentages of students in the experimental schools who met the criteria in the critical thinking skills in science outnumbered those of the students in the comparison schools. Consistent with these findings, the learning achievement of the students in the experimental schools in science is higher than that of the students in the comparison schools as shown in Table 2 and 3. The numbers and percentages of the students who met the criteria in science outnumbered those of the students who were in the comparison schools as shown in Table 3. On the whole, it is believed that the critical thinking skills of the students in the experimental schools in science are literally higher than those of the students in the comparison schools. Perhaps the bilingual education at the first-grade level (grades 1 to 3 ) has laid the foundation of thinking skills for the students. Teachers are trained to use MLE instructional strategies of questioning and allowing students to think out of the box and to express ideas without facing the problem of using various languages. Consistent with the findings of Iamkitphaisarn (2009), that seems to be a strong positive linear relationship $(\mathrm{r}=$ 0.854 ) between the teachings and the analytical ability of the sixth graders. Furthermore, it is in line with the findings of Cabansag (2016) who indicated that MTB-MLE benefited the first and second graders in expressing better ideas, building self-confidence, developing better retention in mathematics, and promoting friendly environment.

\section{Conclusion and Recommendation}

The total 6 years PM-Thai Bilingual Education has succeeded in solving the problems of low and mid-level performing students, who make up the majority of students in the Deep South. Through bilingual education the problem is resolved in the Deep South during the academic years 2010 to 2015, especially for those in the first-grade level. The students in the experimental schools have achieved satisfactory performance at a rate much higher than similar students in the comparison schools. Statistically significant at level.01 the numbers of those who met the criteria outnumbered those of the students in the comparison schools. The education agencies are required to support and implement bilingual education, seriously and continuously in terms of teaching strategies. 
Further, the education departments are required to support teaching materials and organizing budgets to publicize the students' knowledge and abilities that are regarded as the outcome of the project. This support has rendered the community to understand the importance of using the mother tongue as a basis for learning and to appreciate their local culture as their identity.

However, another issue that showed no clear difference in the learning achievement of the sixth graders was the tutoring form of teaching that focused on children's retention for taking an exam. The reluctance for exams can destroy student's potential in higher-order thinking, the development of the brain and the social development of the students. Therefore, the lessons should be taught along the MLE instructional strategies. Moreover, lesson plans should also be developed to develop the student's potential, to meet the curriculum objectives, and to maintain the identity of the community in future.

\section{Acknowledgments}

This article is a revised version of a paper presented at the 5th International Conference on Language and Education: Sustainable Development through Multilingual Education, Land Mark Hotel, Bangkok, Thailand, 1921 October 2016. This research was supported by grants from the UNICEF Bangkok. We are greatly indebted to Emeritus Professor Dr. Suwilai Premsrirat at Center for Documentaion and revitalization of endangered language, RILCA-MU, Bangkok, who not only gave us extremely valuable guidance, but also made available her own resources for our benefits. We are also grateful to Asst. Prof. Dr. Kirk R. Person, SIL International, UNESCO Bangkok, who kindly offered insightful suggestions that greatly improved the manuscript. We thank Dr. Dennis L. Malone and Dr. Susan E. Malone, Certified Senior Literacy and Education Consultants, SIL International, Bangkok for comments that greatly assisted the research.

\section{References}

Breskin, L. (2008). The relationship among ethnic identity, academic achievement, attitudes toward education and gender (Unpublished doctoral dissertation, Hofstra University, New York, United State). Retrieved from http://search.proquest.com/openview/931b9be9388cafac831d7faa8abcceb0/1?pq-origsite=gscholar\& $\mathrm{cbl}=18750 \&$ diss $=\mathrm{y}$

Cabansag, J. N. (2016). The implementation of mother tongue-based multilingual education: Seeing it from the stakeholders' perspective. International Journal of English Linguistic, 6(5), 43-53. http://dx.doi.org/10.5539/ijel.v6n5p43

Chailangka, B. (2006). The Approach towards encouraging the Thai Muslim in Thailand's three southern border provinces to learn and speak Thai (Unpublished master's thesis). Burapha University, Chon Buri, Thailand

Chaipong, S. et al. (2007). The construction of the local curriculum of Phasa Sohng language by the engagement of Tambon Klong Plu and Tambon Takienthong community, Khao Kitchakoot District, Chantaburi province. Nakhon Pathom: Mahidol University. Retrieved from http://research.trf.or.th/node/5852

Chaiwong, A. (2012). Academic administration to raise achievement in ordinary national educational test(O-NET) of Mae Suk School Network, Chae Hom district, Lampang Province under the Lampang Primary Educational Service Area Office 3 (Unpublished master's thesis). University of Phayao, Phayao, Thailand

Dumpheng, S. (2013). Factors affecting the sixth graders' O-NET scores: A Case Study in Ta Phraya district schools under the Sa-Keaw Primary Educational Service Area Office 2 (Unpublished master's thesis). Burapha University, Chon Buri, Thailand.

Farrungsang, B., Uttayawalee, B., Sungtong, E., \& Haji-Awang, F. (2011). Education Reform in Southern Border Provinces. Songklanakarin Journal of Social Sciences and Humanities, 17(6), 157-174. Retrieved from http://edu.psu.ac.th/research/pdf/journal_academic/2554/8-2554.pdf

Iamkitpaisan, O. (2009). Factors affect the ability of students in grade 6 to think critically in Leoi Education Service Area 2 (Unpublished master's thesis). Loei Rajabhat University, Loei, Thailand.

Lemtrakool, W. et al. (2013). Supporting multilingual education of ethnic minority in Northern Thailand: An evaluation study. Lampang: Lampang Rajabhat University.

National Institute of Educational Testing Service. (2009). Crisis of Thai education indicated by O-NET, I-NET, N-NET, GAT and PAT. Bangkok: V. T. C. Communication Ltd., Part.

Office of the Education Council. (2009). The policy development of Thai language instruction in Southern Thailand. Bangkok: Office of Educational Policies and Plans. 
Resource Center for Revitalization and Maintenance of Endangered Languages and Cultures, Research Institute for Languages and Cultures of Asia. (2010). The learning and teaching arrangement by using local language and Thai language: Case study of bilingual (Thai-local Malay) education management in the school in 4 boarder line provinces of the south. Nakhon Pathom: Mahidol University. Retrieved from http://elibrary.trf.or.th/download_fullstep1.asp

Sintana, S. et al. (2013). An assessment of teaching and learning administration by using dialects and Thai as media of instruction: A bilingual case study (Thai and Melayu dialects) in the schools of the four southern border provinces educational region (continuing project). Yala: Yala Rajabhat University.

Sintana, S. et al. (2014). An assessment of teaching and learning administration by using dialects and Thai as media of instruction: A bilingual case study (Thai and Melayu dialects) in the schools of the four southern border provinces educational region (continuing project). Yala: Yala Rajabhat University.

Wiboonsri, R. Y. (2013). Project Evaluation: Concept and Practice (8th ed.). Bangkok: Chulalongkorn University Press.

\section{Copyrights}

Copyright for this article is retained by the author(s), with first publication rights granted to the journal.

This is an open-access article distributed under the terms and conditions of the Creative Commons Attribution license (http://creativecommons.org/licenses/by/4.0/). 